\title{
Lumbar Morphometry: A Study of Lumbar Vertebrae from a Pakistani Population Using Computed Tomography Scans
}

\author{
Safak Ekinci ${ }^{1}$, Faruk Akyildiz ${ }^{2}$, Kenan $\mathrm{Koca}^{3}$, Sebahattin Sari ${ }^{4}$, Serkan Akpancar ${ }^{3}$ \\ ${ }^{1}$ Department of Orthopaedic Surgery, Agri Military Hospital, Agri, Turkey \\ ${ }^{2}$ Department of Orthopaedic Surgery, Malatya Military Hospital, Malatya, Turkey \\ ${ }^{3}$ Department of Orthopaedic Surgery, Gulhane Military Hospital, Ankara, Turkey \\ ${ }^{4}$ Department of Radiology, Gulhane Military Hospital, Ankara, Turkey
}

Dear Editor,

We would like to discuss on the publication entitled "Lumbar morphometry: a study of lumbar vertebrae from a Pakistani population using computed tomography scans [1]". In the study, the authors described the characteristics of lumbar vertebrae of Pakistani patients and compared them with studies from other populations.

Honestly the objective of the study is noteworthy and we have a question for the authors: lumbosacral transitional vertebrae (LSTV) are common in the general population, with a reported prevalence of $4 \%-21 \%[2,3]$. We have studied 500 lumbar plain films and observed 17.6\% transitional lumbosacral junctions $[4,5]$.

Have the authors observed and noted transitional vertebrae in their study or have any other studies/reports on this issue shown correlation with their population?

We would appreciate the authors' comments on this concern.

\section{Conflict of Interest}

No potential conflict of interest relevant to this article was reported.

\section{References}

1. Alam MM, Waqas M, Shallwani H, Javed G. Lumbar morphometry: a study of lumbar vertebrae from a Pakistani population using computed tomography scans. Asian Spine J 2014;8:421-6.

2. O’Driscoll CM, Irwin A, Saifuddin A. Variations in morphology of the lumbosacral junction on sagittal MRI: correlation with plain radiography. Skeletal Radiol 1996;25:225-30.

3. Castellvi AE, Goldstein LA, Chan DP. Lumbosacral transitional vertebrae and their relationship with lumbar extradural defects. Spine (Phila Pa 1976) 1984;9:493-5.

4. Delport EG, Cucuzzella TR, Kim N, Marley J, Pruitt C, Delport AG. Lumbosacral transitional vertebrae: incidence in a consecutive patient series. Pain Physician 2006;9:53-6.

5. Ekinci S, Ersen O. Adolescent idiopathic scoliosis. Arch Clin Exp Surg 2014;3:174-82.

Received Dec 14, 2014; Accepted Dec 15, 2014

Corresponding author: Safak Ekinci

Department of Orthopaedic Surgery, Agri Military Hospital, 04000 Erzurum Caddesi, Agri, Turkey

Tel: +90-5327339850, Fax: +90-4722152747, E-mail: safakekinci@yahoo.com 